\title{
Building Computer Games as Effective Learning Tools for Digital Natives - and Similars
}

\author{
Ismar Frango Silveira, Carlos Fernando de Araújo Jr., \\ Jaime Sandro da Veiga, and Luis Naito Mendes Bezerra \\ Universidade Cruzeiro do Sul, São Paulo, Brazil
}

ismar.silveira@cruzeirodosul.ed; carlos.araujo@cruzeirodosul.ed; jaime.veiga@cruzeirodosul.ed; luis.naito@cruzeirodosul.ed

Leonardo Carlos Comotti Kasperavicius InstantGames Inc., São Paulo, Brazil

leonardo@instantgames.com.br

\begin{abstract}
The use of computer games as learning objects is currently being used as an alternative way to address issues and topics in order to address motivational aspect of students. Digital games can amplify the power of exploration and imagination of students, providing moments of research, reflection and learning. Besides being a strong motivational attractive, computer games could amplify students' potential of exploration and imagination, providing moments that unify recreation to didactics, involving investigation, reflection and learning. The usage of computer games as learning objects is privileged by the playful differential such software category has, compared to conventional learning objects. Using them both in formal and non-formal learning contexts has been proven to be efficient in different aspects. Thus, this paper presents some strategies of using computer games as effective learning tools for students considered as digital natives - or those presenting similar behavioral aspects.
\end{abstract}

Keywords: computer games, learning objects, knowledge building, digital natives, playful learning.

\section{Introduction}

Several authors discuss the use of digital games as effective learning tools. Aguilera and Mendiz (2003) and Gee (2003) bring extensive discussions - and seminal works - on the topic, as Bransford et al. (2000) and Prensky (2001) have done before. The role of digital games in these processes is being explored in the scientific literature for some time already, as evidenced by the work

Material published as part of this publication, either on-line or in print, is copyrighted by the Informing Science Institute. Permission to make digital or paper copy of part or all of these works for personal or classroom use is granted without fee provided that the copies are not made or distributed for profit or commercial advantage AND that copies 1) bear this notice in full and 2) give the full citation on the first page. It is permissible to abstract these works so long as credit is given. To copy in all other cases or to republish or to post on a server or to redistribute to lists requires specific permission and payment of a fee. Contact Publisher@InformingScience.org to request redistribution permission. of Squire (2002). All these authors discuss computer games, as possessors of an attractive addition with strong appeal to motivate children and adults, could amplify the power of exploration and imagination of students, providing moments of research, reflection and learning. Nowadays, more recent discussions bring to light the need for narrative games and applications directed to specific areas such as education in Health 
Sciences (Tashiro, 2009), Engineering (Mayo, 2007) and Computer Sciences (Mustaro, Silva, \& Silveira, 2008), for instance.

Studies on contemporary culture, such as Johnson (2005), lead to the need to address further and specifically on the impact of the games in the education of a young generation of digital natives appropriating the term coined by Prensky (2001). Tapscott (1998) uses the nomenclature "net generation" to describe this generation, characterized by a high degree of autonomy, intellectual openness, inclusion, technology, freedom of expression, curiosity, short-termism and especially confidence.

Shaffer (2007) highlights the use of computer games as effective for children's learning, while Prensky (2007) presents a broader approach, examining the impact of digital games in educational processes in general. Mustaro et al. (2008) argue that this scenario fully justifies even andragogical proposals focused on games, since it is possible to take advantage of nowadays' technological culture to subsidize the construction of learning resources for both formal education and for situations of non-formal learning, for both digital natives and older students that are immersed into (or are strongly influenced by) a culture with a pervasive presence of technology.

The main point behind all these works could be resumed as: the content carried both in formal and non-formal education present some structural problems. Some of them are listed below:

- Content (usually in formal education) have a degree of abstraction that often prevents efficient learning when teaching strategies are used that put students under the condition of passive learners.

- Some learning situations require students to spend huge mental efforts to memorize large amount of information and procedures. This situation occurs equally in formal and nonformal education, being more common in certain knowledge fields than others.

- Presentation of the content in face-to-face education sometime lacks from real-world examples of application of such content. This is more usual in theoretical subjects than hands-on ones.

- Even in practical learning situations, the subject being taught could carry a very high complexity, given the amount of variables involved in real-world experiences. Physics labs and field experiences are good examples of it. These are situations where "real" conditions do not help the learning process - the world could be not so "real" in these cases.

In all these contexts, the application of Information and Communication Technologies (ICTs) in learning and teaching situations could allow new perspectives on various aspects ranging from content organization to a wide range of new opportunities promoted by the effective incorporation of technology into the entire teaching-learning process.

At this point, the concept of Learning Objects (Wiley, 2000) is fundamental for the development of digital educational resources for use both in experimental and large-scale projects involving a massive number of students and disciplines in formal education. However, one of the key points to capture the motivation of learners in situations of computer-mediated teaching and learning lies precisely in how to increase the degree of interactivity of learning objects involved, thus leading to more involving learning experiences.

The resources of the ICT help the interactivity necessary to the process of knowledge building, as well as the organization of the contents to be taught in order to establish a more adequate relationship with learner's daily situations and different levels of abstraction involved in content taught. Computer games are adherent to this proposal, since they represent learning objects that 
join entertaining activities with learning by discovery, presenting everyday situations to students through a playful approach.

Through the use of games, students are able to compare, analyze and experience situations that may be quite close to those experienced in the real world. Moreover, any learning situation can turn into a pleasurable activity and even fun. This statement gains importance especially in learning situations not necessarily connected to a formal educational system, where learners' involvement tends to be lower than in formal ones, which leads high dropouts rates.

\section{How to Produce an Educational Game?}

There are many discussions in literature about processes and lifecycles for game development, as well as for instructional resources. A challenge to be faced is how to put together these cycles in order to produce games as effective educational resources.

Several authors have been adapting the classical software engineering for the development of games (Flynt \& Salem, 2004; Rucker, 2002). In this way, the process of developing games classically a series of steps, as follows (Figure 1):

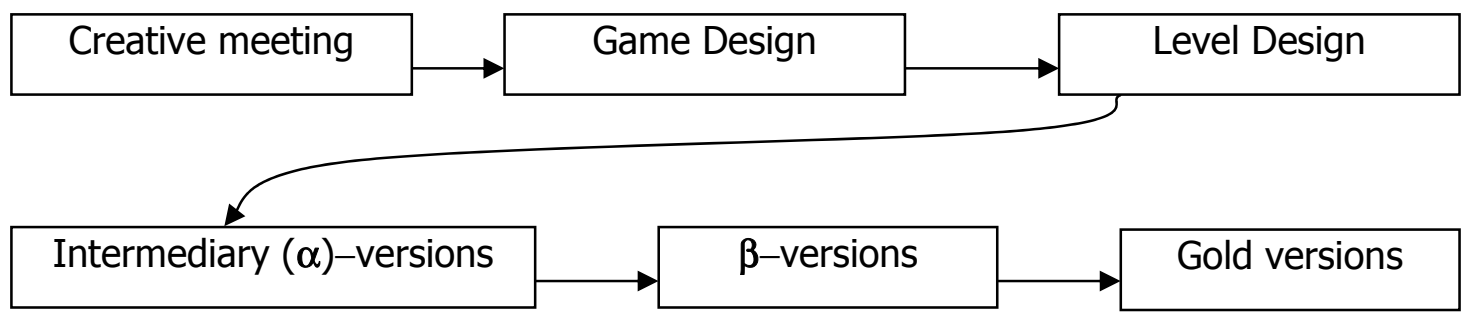

Figure 1. Process of Game Development (adapted from Kasperavičius et al., 2008)

Currently, software development in general, and game development, in specific, have to deal with short-time requirements, being often impracticable to apply classical methods of software engineering. The task of producing software on tight deadlines can be performed through the use of techniques that prioritize agile development (Cockburn, 2002; Highsmith et al., 2001), such as Extreme Programming (eXtreme Programming - XP) (Beck, 1999), among others. Abrahamsson et al. (2002) presents a comprehensive discussion about this subject.

Agile methods prioritize the minimization of risks through the development of software driven by iterations in relatively short time, leading the software team to a review of priorities at each iteration. Such methods have proven effectiveness in software project which are time-limited, with small teams and whose complexity is reasonably low (Sutherland, 2004).

On the other hand, in the context of producing educational resources, Instructional Design models, like ADDIE model - probably the most widely known, define common stages of development, which, insofar as they are observed, provide participants with a well-defined contour of project progress as well as the predictability needed for the teams involved in the project. For instance, ADDIE steps are:

- Analysis - this step is meant to allow teams to understand the problem and propose an educational project for the solution. The analysis step involves the following sub-steps: identifying the learning problem and learning context, list the data to be collected, select the most appropriate methods, locate, construct or modify tools and techniques for the contextual analysis of the project.

- Design - it is when didactical planning and design are made, describing the content and its sequencing. To define strategies and learning activities to achieve the aimed goals, the 
selection of appropriate media and tools and the description of material to be produced are meant to be made in this step.

- Development - comprises the production and adaptation of resources and materials, parameterization of virtual environments and elaboration of pedagogical, technological and administrative support.

- Implementation - this step embraces the application of the resource developed in real teaching-learning situations, in both face-to-face or distance learning situations.

- Evaluation - the resource is evaluated by users (mainly teachers and students), producing educational and learning outcomes to be analyzed.

Nonetheless, ADDIE model has been receiving serious criticisms because of its inherent limitations, specially considering online education, given its scalability. Other models like I CARE (Introduction, Connect, Apply, Reflect, Extend), OAR (Objectives, Resources, Activities), LADR (Lecture, Application, Discussion, Reflection), APT (Analyse, Practice, Talk), or Rapid Prototyping - which is usually been cited as a way to improve ADDIE model. Anagnostopoulo (2002) brings a deeper discussion about this subject, whilst Figure 2 shows an example of how these models are similar in many aspects.

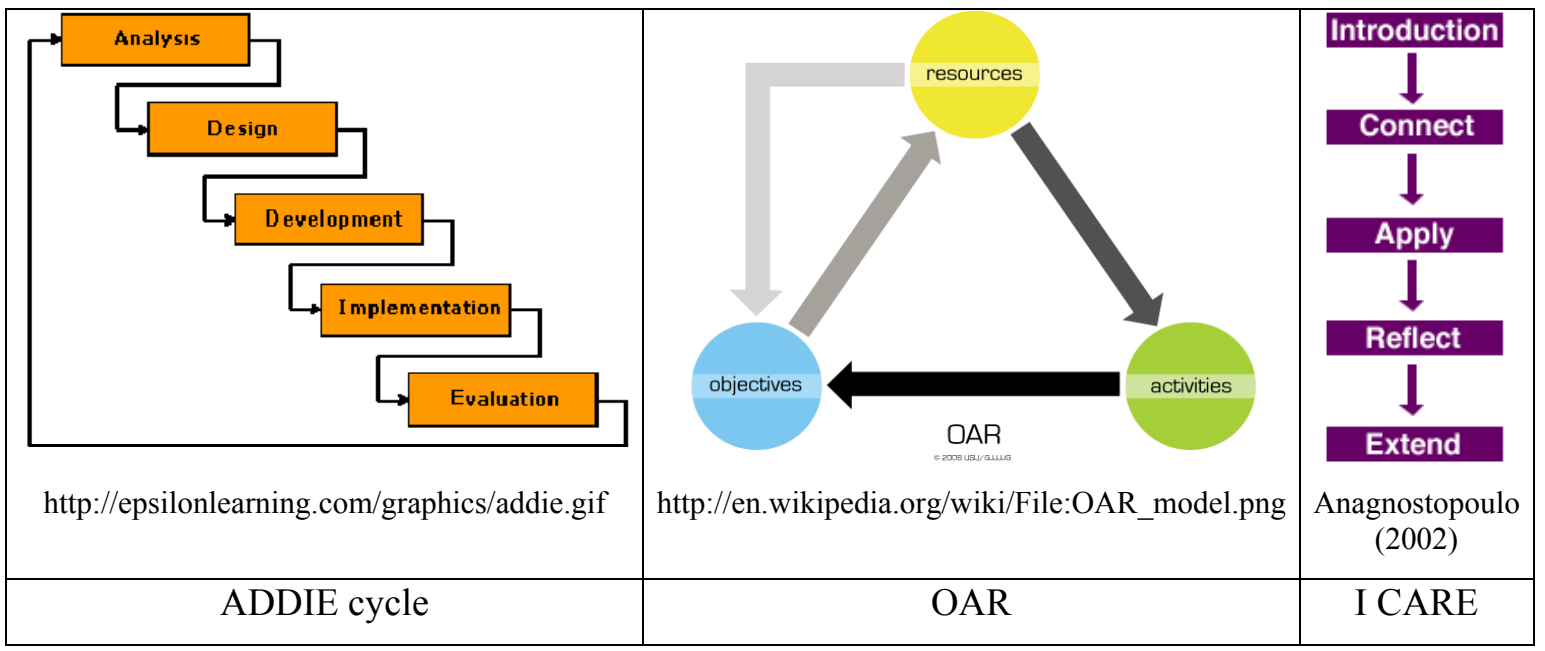

Figure 2. Some processes of Instructional Design

Joining both areas Table 1 and 2 - adapted from Kasperavicius et al. (2010), show the common process of producing digital-based learning objects, including computer games.

Table 1: Production process of educational games

\begin{tabular}{|c|c|c|c|}
\hline Media & Step 1 & Step 2 & Step 3 \\
\hline Computer $\mathbf{G a}$ & $\begin{array}{l}\text { Storytelling } \\
\text { Prototyping } \\
\text { Initial content }\end{array}$ & $\begin{array}{l}\text { Game design and project } \\
\text { Game programming } \\
\text { Content insertion } \\
\text { Audio tracking } \\
\text { Professor's guide }\end{array}$ & $\begin{array}{c}\text { External Evaluations } \\
\text { Final Analysis } \\
\text { Finalization }\end{array}$ \\
\hline
\end{tabular}


Table 2: Production process of digital learning objects (other than games)

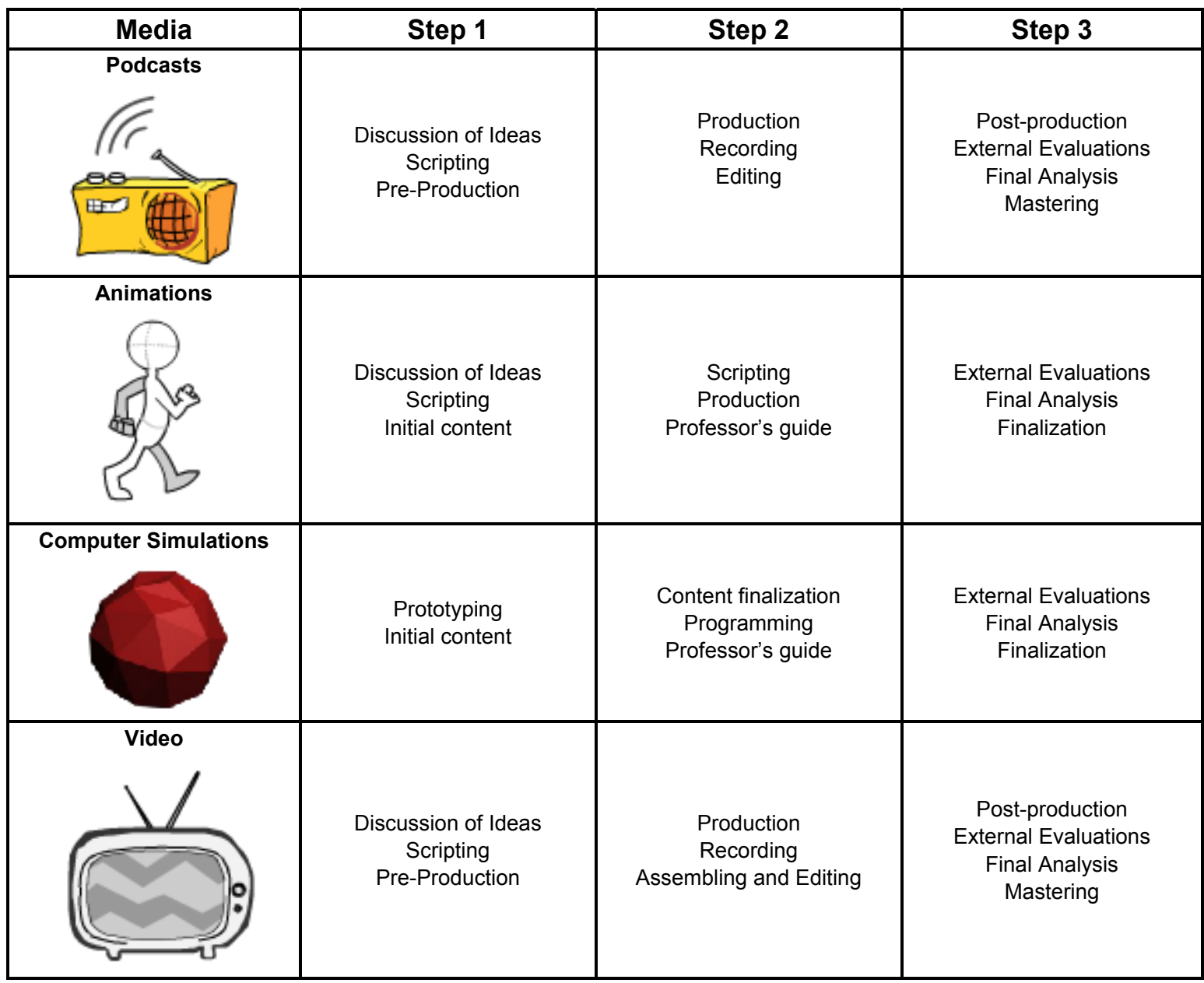

From Table 1 and 3, it could be concluded that the processes involving game development as effective learning objects must consider the idiosyncrasies that involve all educational project, but not forgetting the specificities that are unique to game engineering process.

\section{From Real-Life Simulations to Fantastic Realism: Learning Through Ludic Situations}

As stated before, playful activities could be a key to capture the motivation of learners in computer-mediated teaching and learning situations, since one of the levels of knowledge acquisition defined by Gagné et al. (1992) lies precisely in increasing the degree of interactivity of learning objects involved in the process.

Thus, the use of simulations and computer games as learning objects might overcome these growing demands present in teaching and learning situations that are driven by interactionist teaching methodologies, such as constructivism or meaningful learning (Ausubel, 1963). Koohang et al. (2009) present a deeper discussion about constructivism and computer-mediated learning.

In this sense, it is necessary to define learning and teaching objectives in a given didactical situation in order to be able to project the right digital resources that would fit these objectives. Thus, when planning computer educational games, the specific objectives must guide developers about: 
- the type of knowledge students are expected to build - opposing procedural to informational knowledge, as in Silveira \& Ferreira (2003),

- the kind of learning situation students are meant to be faced to, and

- the category of learning (here opposing meaningful to rote learning) the digital resource will provide students.

Once these main goals are defined, game designers and content producers could define better the first game documents, including making an important decision: will the game tend to fantasybased scenarios, scripts and situations or will it more keen to real-world situations? This decision, although seeming to be of a lower level of importance, in fact plays a decisive role when educational games are produced.

Figure 3 depicts an approximated situation that mixes these important variables when planning and educational game.

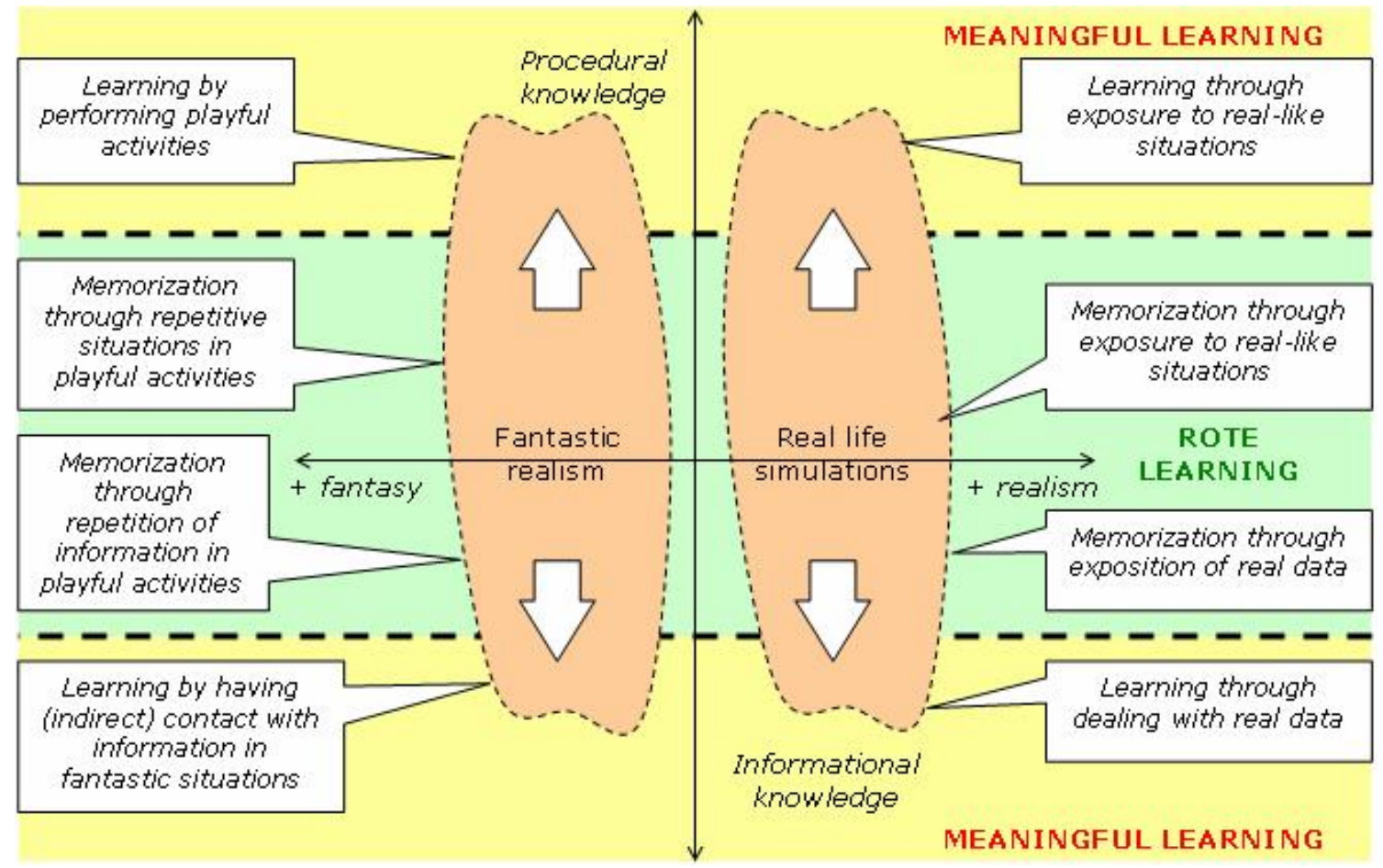

Figure 3. From realism to fantasy: types of knowledge and categories of learning

As seen in Figure 3, the usage of games itself is not enough to guarantee meaningful learning situations, since even playful activities could be done dealing with simpler cognitive processes as memorization. These situations, usual in rote learning, are made possible by educational games with simpler mechanics that prioritize repetitive situations or pieces of information. On the other hand, meaningful learning situations could be provided by designing games where students could deal with playful situations, being stimulated to having contact (even indirect) to pieces of information (in the case of informational knowledge being the target of learning process) or being required to perform some real-world (or even not so real) activities that would provide the building of cognitive structures responsible for procedural knowledge.

Next sessions will present some games developed by Cruzeiro do Sul University team in Brazil, in the context of two different projects: "First Driver's License", executed from 2007 to 2008 and "Digital Contents for High School Math", executed from 2008 to 2010. 
The "First Driver's License" project, developed in a partnership with a private venue, aimed to develop computer games related to the national qualification exams for driver's license - in Brazil, it is allowed to drive from the age 18, perhaps the right target audience for game-based learning. The other project, "Digital Contents for High School Math", was sponsored by Brazilian's Ministry of Education, and had as its main goal develop learning objects for Sciences and Math for High school - the University chose develop educational games for Math, based in a wide scientific literature, like Kay and Knaack (2008), for instance. Both produced educational games that cover different educational requirements about the type of knowledge expected to be built, combined with different game structures, as it will be seen next.

\section{Real-life Simulations and Informational Knowledge: "The Directional Signals Game"}

An extremely hard lesson to be learned by those (usually young) beginner drivers that are doing their preparation for qualification as a driver license's possessor is the large number of directional signs that must be memorized. In Brazil there are over 120 regulatory and warning signs, and this is one of the topics of the theoretical test to obtain the driver's license.

The memorization process is usually dull, often because the candidates have only a printed manual as a support for this task. In order to help the memorization process of the signs, the "Directional Signals Game" - first presented in Kasperavičius et al. (2008), was created having as a reference a memory game with all the signs, whose some screenshots can be seen in Figure 4 below. This game is part of "First Driver's License" project.
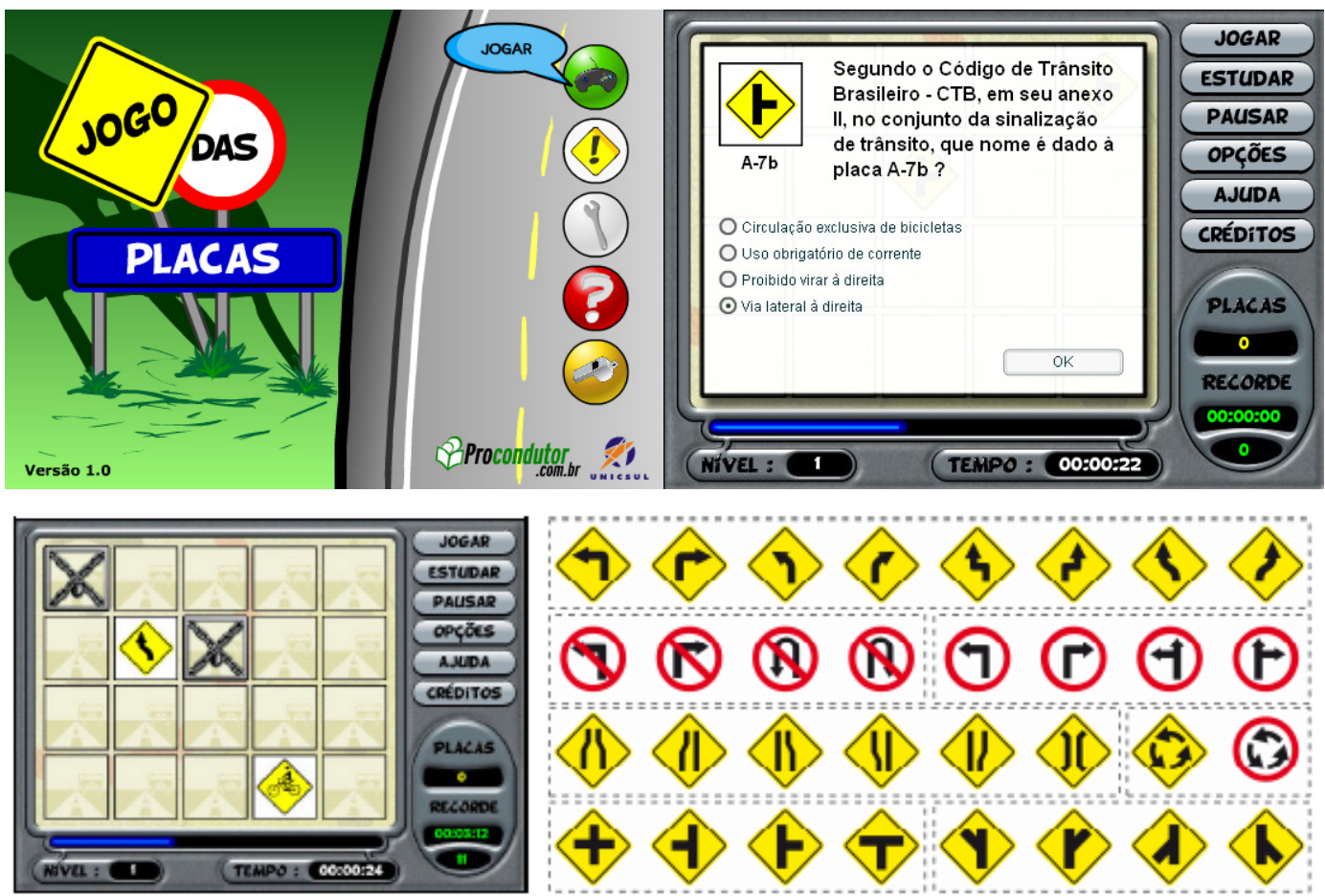

Figure 4. Screens of the game, clockwise: splashscreen, an exam-like question (in Portuguese), some directional signals and the memory game-based screen

The game was based on conventional memory games where you must find pairs of pictures / letters randomly on a table. In the game, ten pairs of cards with the traffic signs are shuffled and arranged on the screen, with their backs turned to user. The user chooses two cards to find a pair, and each pair of plates found the user must also set the card name from among four options pro- 
vided (Figure 4). Hitting the name plate, the pair leaves the tray and counts one point. When no more cards remain on the board, ten more are drawn and distributed again, moving well to a new level of play.

The objective of this game was clearly forcing the memorization of signs - which is a kind of informational knowledge, by presenting real signs with exam-like questions through a playful activity - the memory game, in this case.

A modified version of this game is still in use in driving schools at São Paulo state, Brazil.

\section{Real-life Simulations and Procedural Knowledge: "Four-Wheels Simulator", "Two-Wheels Simulator," and "Wasting the Monthly Allowance"}

"Four-wheels simulator" and "Two-wheels simulator", part of the "First Driver's License" project, were games whose goal was making users more familiar to the tasks that are meant to be performed during the actual driving practical exam that is usually held on the streets of Sao Paulo, Brazil. Both are technically described in Kasperavičius et al. (2008).

Figure 5 shows (clockwise) some screenshots of the following steps associated with the practical examination: Setting up the vehicle, Beacon test, Slope test and Mandatory stop step. At each stage there are shown messages with some tips about the task and the exam itself.
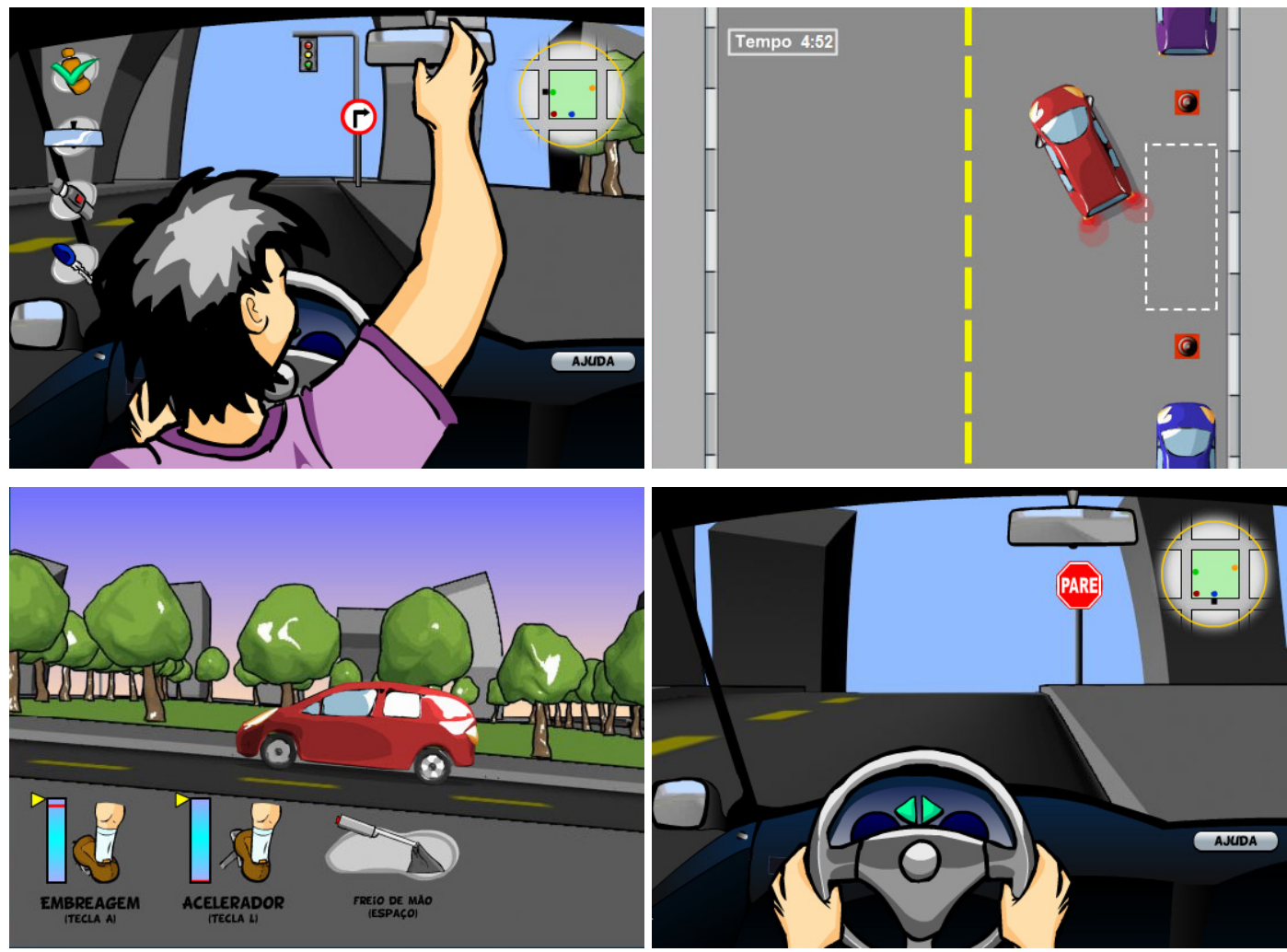

Figure 5. "Four-wheels Simulator" screens

Obviously, the game could be classified as a real-world simulation. As a first approach, a very realistic simulation was planned, where the user must give all commands to the vehicle during the trip (as in the real vehicle). But, after some testing session, it could be seen that the complexity to handle the keyboard controls and camera associated with the vehicle ended up blurring game's main goal, since in most cases users could not even start the vehicle. Thus, the second version 
tried to reduce many of the controls used during the game, also putting on it a cartoon-like appearance, without losing the real aspects of the game.

This approach was used also in the motorcycle version of this game, the "Two-Wheels Simulator", when the real road that is used in exams was studied and mapped into the game, since in this case learning how to deal with the challenges of the real path is significant to be approved in the exam. Figure 6 shows (clockwise) the game map that had been drawn up based on real circuit, located in Ibirapuera Park, Sao Paulo, Brazil, and some screens of the game.

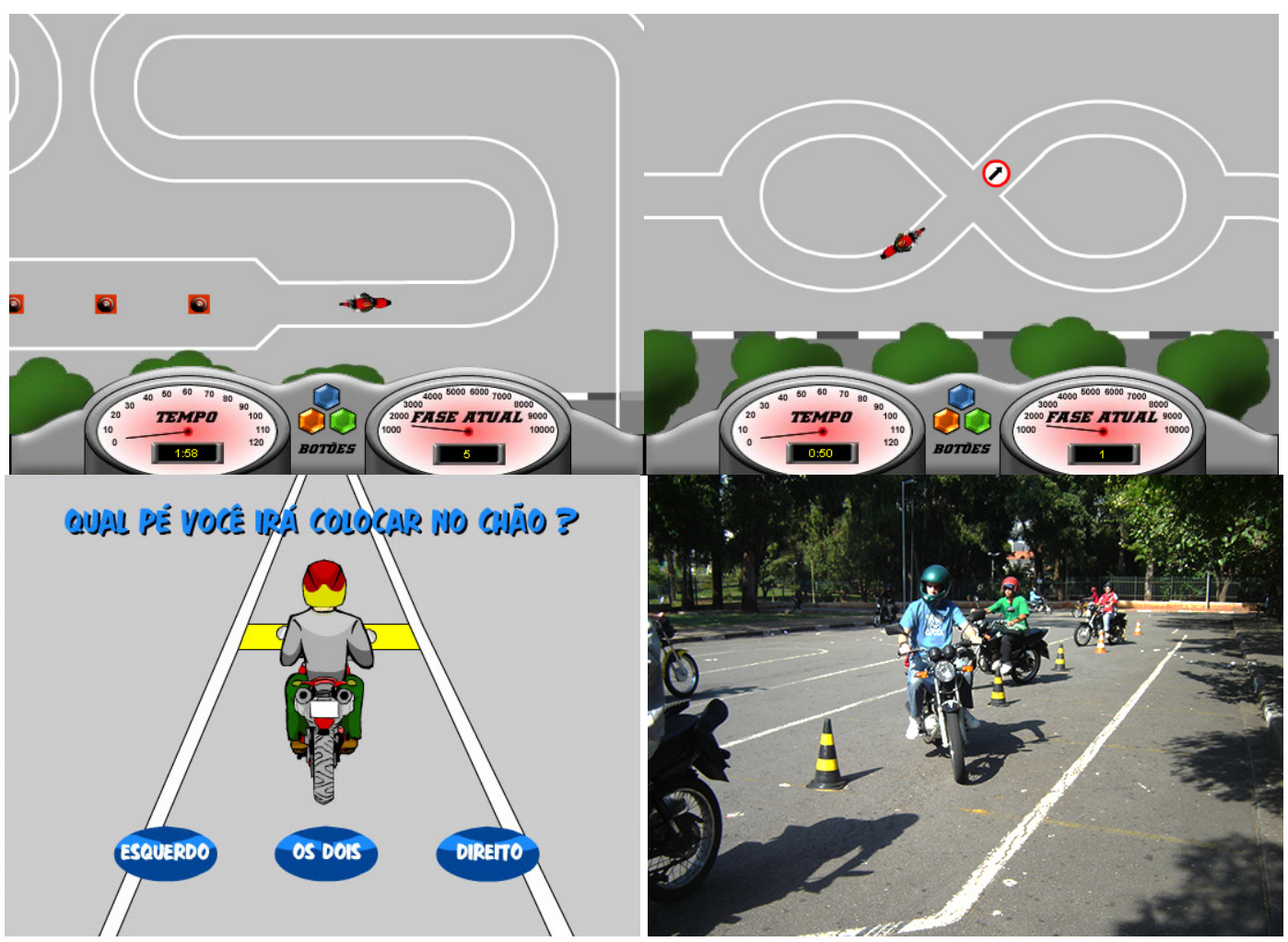

Figure 6: "Two-wheels simulator" screens (clockwise): two parts of the game map, a picture of the actual circuit and a question (in Portuguese) about which foot would bear the motorcycle.

The kind of knowledge that candidates are meant to build is mostly procedural, since they are related to a set of tasks to be performed and operations to be learned - even though some memorization is required (the order of steps to start up the vehicle, for instance).

Both games are useful in order to help applicants to get familiar with the tasks, circuits and expected actions - through a brief survey with examiners, it was found that many applicants make mistakes due only to forgetfulness or simply because they usually turn nervous and not confident during the exam.

Another example of a real-world simulation with cartoon-like aesthetics is the game "Wasting the Monthly Allowance", this one part of the second project. The main goal of this board game was to allow students to build some fundamental knowledge about Financial Math, like interest rates, discounts, bank accounts, and so on. This game, first presented by Silveira et al. (2009), has a deeper technical description in Kasperavičius et al. (2010).

The game's storytelling is based on the story of a teenager who has just entered high school and has given a credit card from his parents in order to manage his/her own finances. The student should try to garner the highest possible value on possessions and the smaller amount of debt at 
the end of the "year" (a complete turn on the board, that mimes a shopping mall), besides having a few missions to undertake to help parents in the repair of a refrigerator, or go to the movies regularly, for example. Figure 7 and 8 show some screenshots of it.
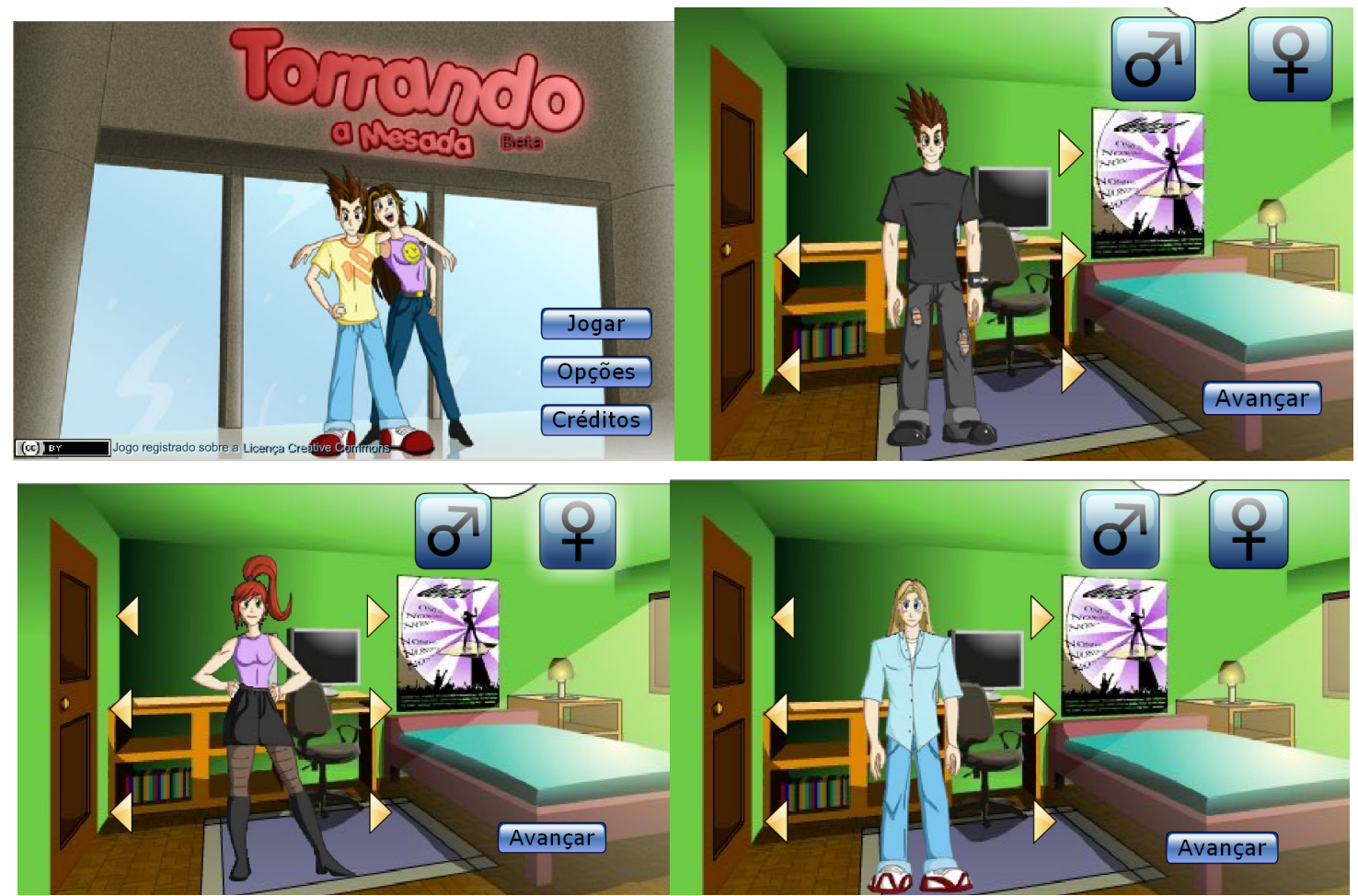

Figure 7: Game's splashscreen and screens for avatar's customization
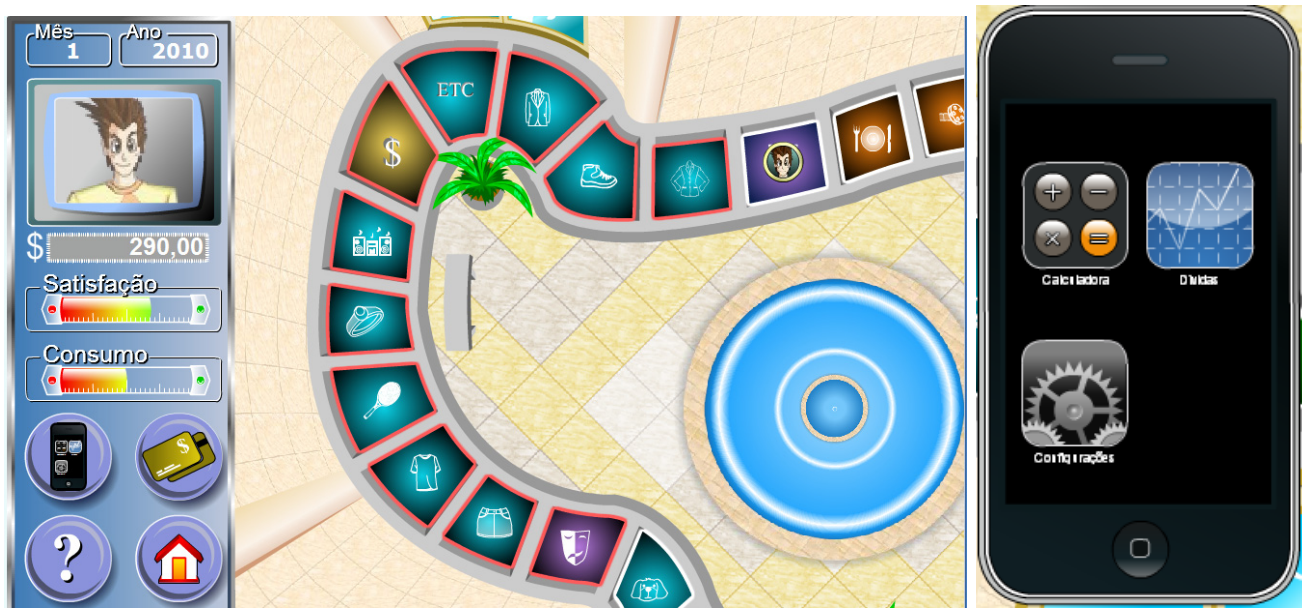

Figure 8: Main board and (iPhone-like) auxiliary calculator

Being another example of world-like simulator, the game aims to help students to build their own procedural knowledge by problem solving activities involving Financial Math fundamentals.

\section{Fantastic Realism and Informational Knowledge: Pi's Journey}

The game "Pi's Journey", part of the "Digital Contents for High School Math" project and first presented by Silveira et al. (2008), addresses the topic of Numerical Sets through a narrative based on fantastic realism. It is the history of the number $\pi$ in search of his identity - a clear allu- 
sion to the historical references on the numbers, reporting that the ancient Hebrews incorporated a natural value to $\pi=3$, as the Babylonians indicated a rational value for $\pi=31 / 8$. Thus, the dynamics of the game, interspersed with a narrative play, leads the student to work with the concepts of belonging to sets of numbers.

The game, originally developed in Adobe Flash, was recently ported to Apple's iPhone and iPad. For both platforms, it is already translated into English and Spanish. Figure 9 shows some screenshots of the game's narrative (focusing on the cut scenes).

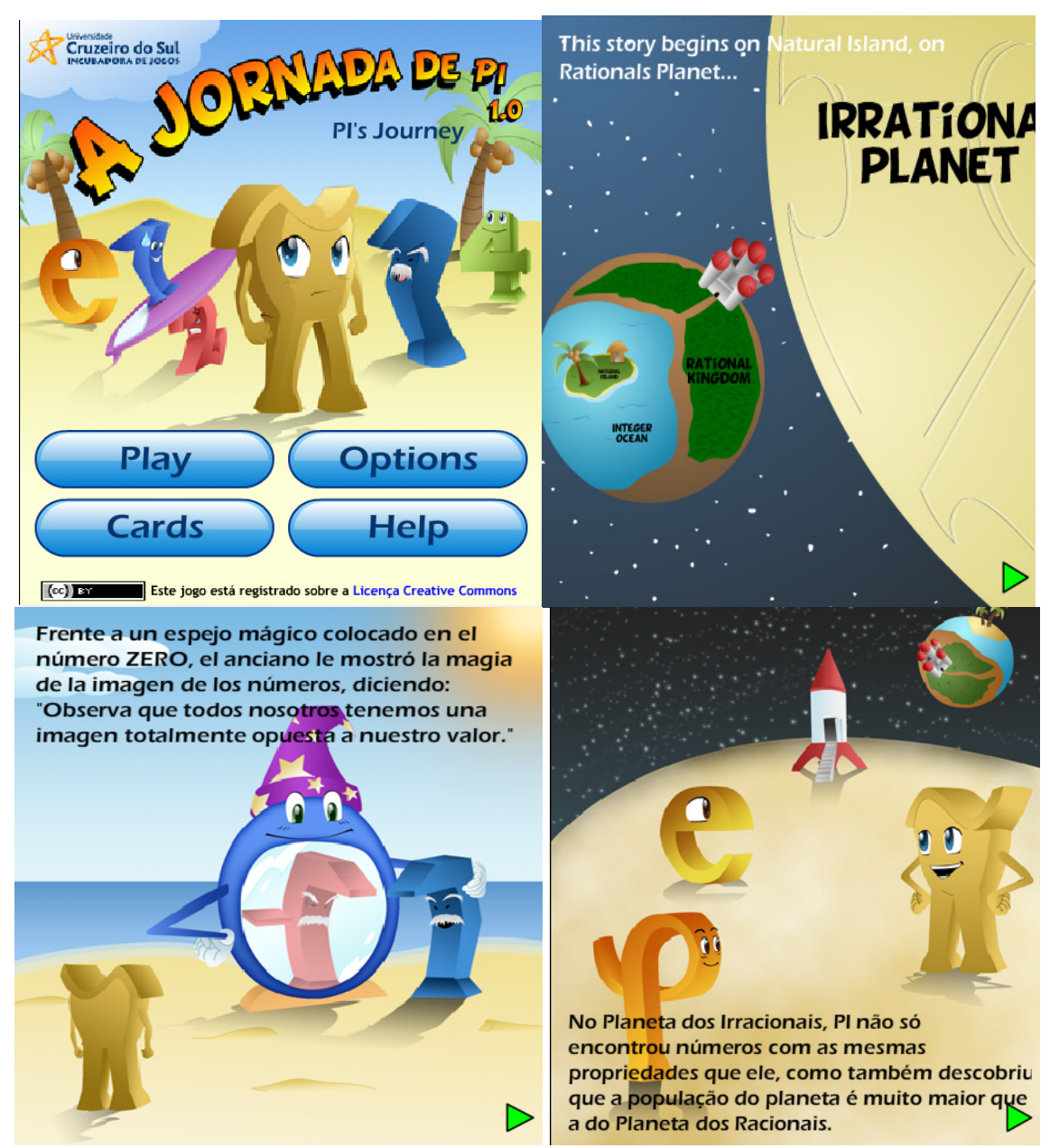

Figure 9 (clockwise): Splashcreen and cut scenes in English, Portuguese and Spanish.

Figure 10 shows, at left, the second level of the game (there are 5 levels total) where Pi's character is tasked to identify the numbers belonging to the sets $\mathrm{N}$ and Z-N, by changing the color of the basket with which he must capture the numbers. The right side of the figure shows game as ported and adapted for iPhone (with support for accelerometer features and online score). 

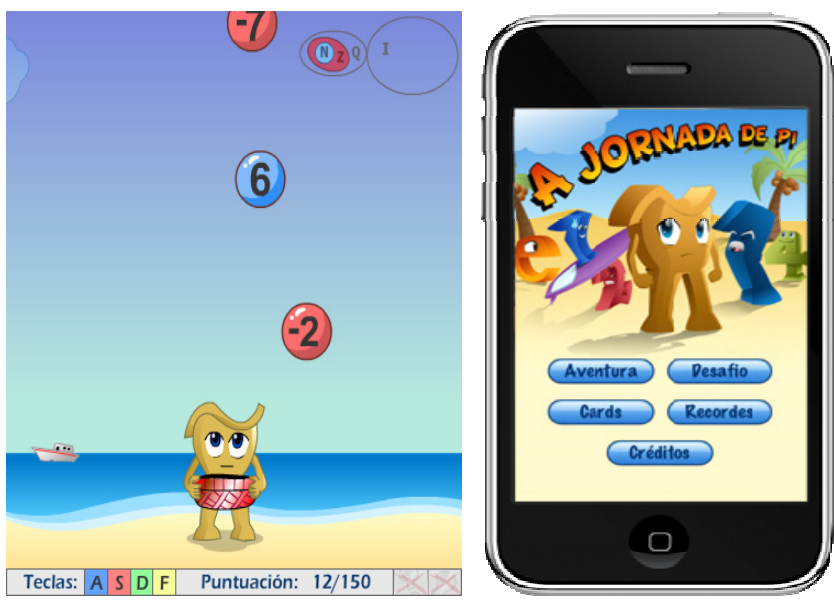

Figure 10 (clockwise): Level 2 (in Spanish) and iPhone version (in Portuguese)

The type of knowledge students are meant to build is essentially informational, but it goes beyond the simple memorization of facts, since it is required of students to identify which properties a numeral has to have in order to belong or not to a given numeric set.

\section{Fantastic Realism and Procedural Knowledge: Sequential Invaders}

Also using a fantasy-based narrative, the "Sequential Invaders" game (part of the same project of previous game), has as its main goal is to protect the planet Earth from asteroids. For this, students are challenged to destroy the asteroids that menace Earth, but they only can be destroyed if they are part of an Arithmetic or Geometric Progression - all asteroids are labeled with integers. Figure 11 shows a set of asteroids attacking Earth and some of them selected, forming an Arithmetic Progression.

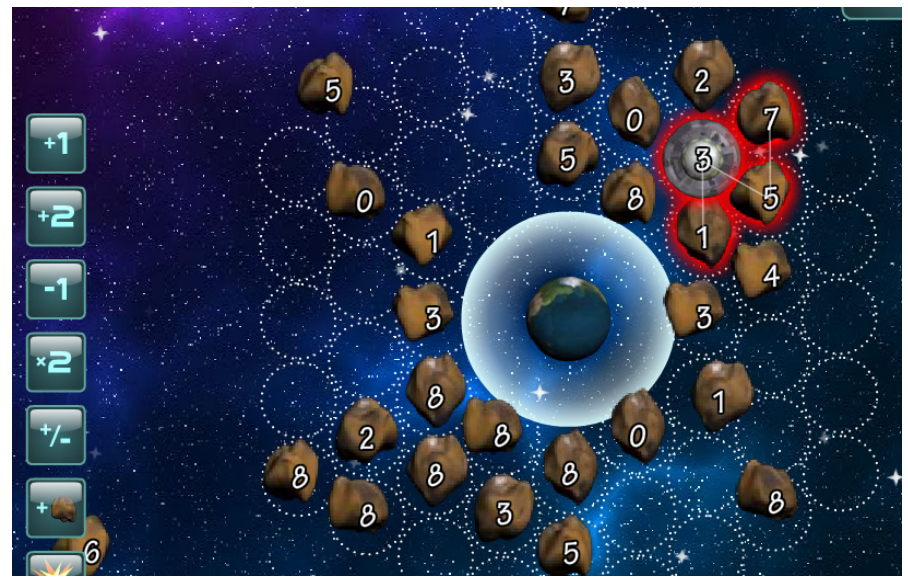

Figure 11: Learning Arithmetic and Geometric Progressions through a fantastic realism-based game

This game is an example of how fantastic realism situations could be used to help students to build procedural knowledge. Students are meant to understand how a sequence is formed, exercising his/her arithmetic skills. Student can also use extra resources (named "magics") that are made available to him/her according to the number of asteroids destroyed. These "magics" allow him to change numbers' signs, or add or subtract numbers so they can be part of a sequence. By 
doing this, students can exercise beyond his knowledge on the topic, creativity and strategic thinking.

\section{Conclusions}

Different types of knowledge require distinct ways of designing and developing educational resources that could effectively support the process of learning. Computer games have been proven as potentially effective digital resources for learning. But games themselves are not capable to guarantee a specific type of learning - meaningful learning, for instance - since it depends not only on the tool being designed, but it mainly relies on the learning objectives.

Thus, diverse learning objectives - which involves types of knowledge and strategies of teaching and learning - allied to different game styles - which involves storytelling, aesthetics, game mechanics, and so on - could also result in distinct impacts in the whole process. In this direction, this paper showed some examples of games with different styles that tried to fulfill distinct requirements.

Further works point to the need for a more detailed analysis of the applicability of the games and the relationships among types of knowledge, learning theories and game styles.

\section{References}

Abrahamsson, P., Salo, O., Ronkainen, J. E., \& Warsta, J. (2002). Agile software development methods Review and analysis. Vuorimiehentie, Finland: VTT Pub.

Aguilera, M., \& Mendiz, A. (2003). Video games and education: (Education in the face of a "parallel school"). Computers in Entertainment, 1(1), Article 1.

Anagnostopoulo, K. (2002). Designing to learn and learning to design: An overview of instructional design models. White paper, LTSN Generic Centre. Retrieved December $1^{\text {st }}, 2010$, from http://www.jiscinfonet.ac.uk/InfoKits/effective-use-of-VLEs/resources/ltsn-instructional-design$\underline{\text { models }}$

Ausubel, D. P. (1963). The psychology of meaningful verbal learning. New York: Grune \& Stratton.

Bransford, J., Brown, A., \& Cocking, R. (2000). How people learn: Brain, mind, experience, and school. Washington: National Academy Press.

Cockburn, A. (2002). Agile software development (3rd ed.). Addison Wesley Professional.

Flynt, J. P. \& Salem, O. (2004). Software engineering for game developers. Sebastopol, EUA: PTR Prentice-Hall.

Gagné, R., Briggs, L., \& Wager, W. (1992). Principles of instructional design (4th ed.). Fort Worth, TX: HBJ College Publishers.

Gee, J. P. (2003). What video games have to teach us about learning and literacy. New York: Palgrave Macmillan.

Highsmith, J. et al. (2001). The agile manifesto. Retrieved October 28, 2010 from http://agilemanifesto.org/

Holim, S. (2009). Distance learning technology, current instruction, and the future of education: Applications of today, practices of tomorrow. New York: Idea Group Publishing

Johnson, S. (2005). Everything bad is good for you: How today's popular culture is actually making us smarter. New York: Riverhead.

Kasperavičius, L. C. C., Miranda, R. L., Silveira, I. F., \& Araujo, C. F., Jr., (2010). . Gestão de Projetos de Objetos de Aprendizagem Multimidiáticos com Equipes Multidisciplinares. In: Proceedings of V LACLO - Latin-American Conference on Learning Objects, São Paulo, Brazil, p. 499-505. (in Portuguese). 
Kasperavičius, L. C. C., Bezerra, L. N. M., Silva, L. \& Silveira, I. F. (2008). Ensino de Desenvolvimento de Jogos Digitais Baseado em Metodologias Ágeis: o Projeto Primeira Habilitação. In: Proceedings of XXVIII Brazilian Computer Society Conference, Belém, Brazil, p. 89-98. (in Portuguese)

Kay, R., \& Knaack, L. (2008). Investigating the use of learning objects for secondary school mathematics. Interdisciplinary Journal of E-Learning and Learning Objects, 4, 269-290. Retrieved from http://www.ijello.org/Volume4/IJELLOv4p269-289Kay.pdf

Koohang, A., Riley, L., \& Smith, T. (2009). E-learning and constructivism: From theory to application. Interdisciplinary Journal of E-Learning and Learning Objects, 5, 91-109. Retrieved from http://www.ijello.org/Volume5/IJELLOv5p091-109Koohang655.pdf

Mayo, M. J. (2007). Games for science and engineering education. Communications of the ACM, 50(7), 3035 .

Mustaro, P. N., Silva, L., \& Silveira, I. F. (2008). Using games to teach design patterns and computer graphics. In Richard E. Ferdig (Org.). Handbook of research on effective electronic gaming in education (1st ed., v. II, pp. 525-545). Hershey, PA, USA: Information Science Reference - IGI Global.

Prensky, M. (2001). Digital game-based learning. Minnesota: Paragon House.

Rucker, R. (2002). Software engineering and computer games. New Jersey, USA: Addison-Wesley.

Sans, M. J. B., \& Domingues, R. H. (2000). Mathematical games: Through play, children solve problem situations. Teacher Magazine, 16(61), 5-9.

Shaffer, D. W. (2007). How computer games help children learn. New York: Palgrave MacMillan.

Silveira, I. F., Araujo, C. F., Jr., Kasperavicius, L. C. C., Veiga, J. S., Lima, V. S., Amaral, L. H., Calejon, L. M. C., Curi, E., Santos Filho, V., Bezerra, L. N. M., Ledón, M. F. P., Schimiguel, J., \& Mustaro, P. N. (2008). Diseño Instructivo de Objetos de Aprendizaje de Matemática Basado en Juegos Digitales: un Abordaje Integrado a TV y Radio. In: LACLO2008 - 3ra. Conferencia Latinoamericana de Objetos de Aprendizaje, 2008, Aguascalientes, Mexico. Proceedings of LACLO2008. (in Spanish)

Silveira, I. F., Araujo, C. F., Jr., Kasperavicius, L. C. C., Veiga, J. S., Miranda, R. L., Tarcia, R. M. L., Mustaro, P. N., \& Cabral, A. L. T. (2009). Jogos e Simulações como Objetos de Aprendizagem para o Ensino de Matemática. In: LACLO 2009 - IV Conferencia Latinoamericana de Objetos de Aprendizaje, 2009, Mérida, México. Proceedings of CcITA 2009 - Conferencia Conjunta Iberoamericana sobre Tecnologías de Aprendizaje. (in Portuguese)

Silveira, I. F., \& Ferreira, M. A. G. V. (2003). Gathering new knowledge and skills by shared 3D learning objects across a virtual classroom. In $4^{\text {th }}$ International Conference on Information Technology Based Higher Education and Training, Marrakech, Morroco. Proceedings of ITHET'2003, p. 329-333.

Squire, K. D. (2002). Rethinking the role of games in education. Game Studies, 2(1). Retrieved November 11, 2010 from http://www.gamestudies.org/0102/squire/

Tapscott, D. (1998). Growing up digital: The rise of net generation. New York: McGraw Hill.

Tashiro, J. (2009). What really works in serious games for healthcare education. Proceedings of the 2009 Conference on Future Play. Vancouver, Canada. 


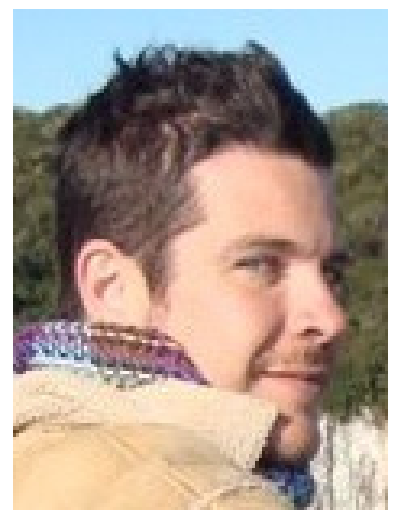

\section{Biographies}

Ismar Frango Silveira earned his degree in Mathematics-Informatics, at Federal University of Juiz de Fora (1994); Master of Science (Area: Computer Graphics) by the Institute of Aeronautical Technology (1997) and his Ph.D. in Electrical Engineering (Area: Distributed Virtual Reality Applied to Education) by University of São Paulo (2003). $\mathrm{He}$ is currently Professor at Mackenzie Presbyterian University and Cruzeiro do Sul University, both in Sâo Paulo, Brasil. His research concentrates on Digital Games, Learning Objects, Collaborative virtual environments, and ICT for Education in general.

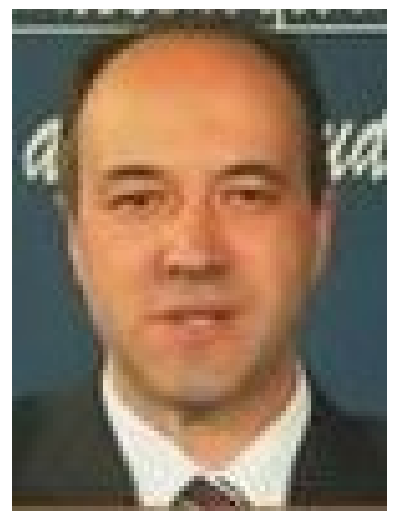

Carlos Fernando de Araújo Jr. graduated with Master in Physics from Universidade Estadual Paulista Julio de Mesquita Filho (1990, 1993) and Ph.D. in Theoretical Physics from the same university. In recent years, in addition to research activities in the Master's program in Teaching Science and Mathematics, he has been Course Coordinator, Dean's Advisor, and Director in the IT area at Cruzeiro do SUl Univeristy, in São Paulo - Brazil. of Technology and Computing. His research areas include Technology-enhanced education, virtual learning environments, distance education, teaching of Math, Science and CS.

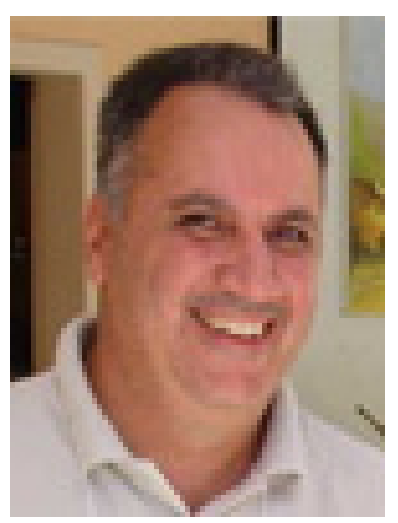

Jaime Sandro da Veiga holds a BSc. in Physics from the University of São Paulo (1988), Masters (1993) and PhD in Physics from the Institute of Theoretical Physics UNESP (1996). It has two Postdoctoral internships, including one by the Institute of Physics, University of São Paulo (1996-1999) and the other from the California Institute of Technology (Caltech) (1999-2000) in the USA. He is currently a professor at Cruzeiro do Sul University and coordinator of the Specialization Course for Officers of the Fire Brigade São Paulo State in the key area. He teaches at Masters Program in Education and Doctorate of Science and Mathematics researching the areas of "New Methodologies for the Teaching of Physics and Mathematics" and "Distance Learning", with special attention for teaching modern physics in high school and the production of multimedia content in distance learning of Mathematics.

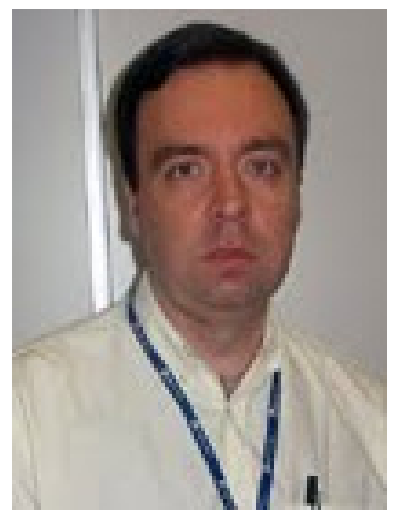

Luis Naito Mendes Bezerra has a degree in Accounting with Emphasis in Systems Analysis - Associated Colleges of São Paulo (1990), Master in Production Engineering (Area: Information Management) from Paulista University (2005) and Master of Science (Area: Information Systems) Guarulhos University (1998). He is currently a professor at Cruzeiro do Sul University, Brazil. He has experience in Computer Science with emphasis in Information Systems, acting on the following topics: information technology, digital games, operating systems and databases. 


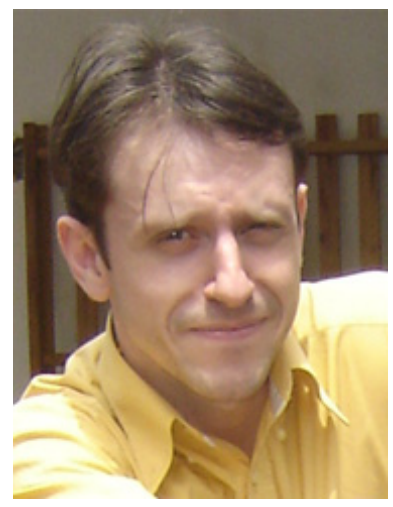

Leonardo Carlos Comotti Kasperavičius graduated in Computer Science from Southern Cross University (2004) and has a postgrduation in Web Engineering (2005). He used to work at Cruzeiro do Sul University as a teacher. Besides being a SCJP/SCWCD certified, he has experience in developing web and desktop systems, and nowadays he owns Digital Game company, specialized on mobile games, focused mainly in iPad and iPhone market. 